\title{
Long non-coding RNA H19 knockdown inhibits the cell viability and promotes apoptosis of thyroid cancer cells through regulating the PI3K/AKT pathway
}

\author{
XIAOYU LI ${ }^{1}$, QINGHUAI LI ${ }^{1}$, XIAO JIN ${ }^{1}$, HAO GUO $^{1}$ and YONG LI ${ }^{2}$ \\ ${ }^{1}$ Department of Thyroid and Breast Surgery, The Second Hospital of Hebei Medical University, Shijiazhuang, Hebei 050000; \\ ${ }^{2}$ The Third Department of Surgery, The Fourth Hospital of Hebei Medical University, Shijiazhuang, Hebei 050011, P.R. China
}

Received October 30, 2018; Accepted May 10, 2019

DOI: $10.3892 /$ etm.2019.7720

\begin{abstract}
Certain long non-coding (lnc)RNAs have been reported to serve important roles in the genesis and progression of thyroid cancer (TC). Recent studies have demonstrated that the expression of lncRNA H19 is upregulated in TC tissues; however, knowledge of the associated molecular mechanisms is limited. Therefore, the present study aimed to clarify the roles of H19 in TC. The mRNA expression of lncRNA H19 in TC tissues was determined using reverse transcription-quantitative polymerase chain reaction analysis, and the effects of H19 knockdown on cell viability and apoptosis in vitro were assessed using MTT and flow cytometric assays, respectively. Finally, the signaling pathways involved in the effects of H19 were examined. The results indicated that H19 was upregulated in TC tissues. Silencing of $\mathrm{H} 19$ inhibited the cell viability and promoted apoptosis of FTC-133 and TPC-1 TC cells, accompanied by an increased expression of B-cell lymphoma 2 (Bcl-2)-associated $\mathrm{X}$ protein and caspase 3 , and repressed expression of $\mathrm{Bcl}-2$. The results of western blot analysis suggested that the levels of phosphorylated phosphoinositide- 3 kinase (PI3K) and phosphorylated AKT were attenuated by H19 silencing. These results suggest that lncRNA H19 exerts an oncogenic function in TC, in part through the PI3K/AKT pathway.
\end{abstract}

\section{Introduction}

Thyroid cancer (TC) commonly presents in women of all ages and is associated with a high morbidity, worldwide $(1,2)$. Despite the high survival rates of affected patients, an increasing incidence combined with a high rate of recurrence and a young age at diagnosis indicates that additional research

Correspondence to: Dr Yong Li, The Third Department of Surgery, The Fourth Hospital of Hebei Medical University, 12 Jiankang Road, Shijiazhuang, Hebei 050011, P.R. China

E-mail: yong11@yandex.com

Key words: thyroid cancer, H19, cell viability, apoptosis on TC is required (2,3). Follicular thyroid carcinoma (FTC) accounts for almost $15 \%$ of all cases of TC (4).

Long non-coding RNAs (lncRNAs) are a class of non-protein-coding transcripts that are $>200$ nucleotides in length (5). Increasing evidence indicates that lncRNAs are crucial factors in tissue physiology and the pathological processes of various diseases, including cancer $(6,7)$. A large number of dysregulated lncRNAs have been identified in cancer, suggesting their oncogenic or tumor-suppressive properties $(8,9)$. IncRNAs have been reported to serve an important role in the oncogenesis and progression of TC $(10,11)$. For example, the lncRNA PTC susceptibility candidate 3 , which is specifically expressed in thyroid tissues and downregulated in PTC tissues, has been reported to function as a tumor suppressor through the $\mathrm{S} 100$ calcium-binding protein A4 pathway $(12,13)$. In addition, the expression of BRAF-activated lncRNA (BANCR) was found to be higher in PTC tissues compared with that in matched normal tissues, and BANCR has been reported to contribute to the genesis of PTC through regulating cell proliferation and the cell cycle $(14,15)$.

Recent studies have indicated that expression of lncRNA H19 is upregulated in TC tissues and TC cell lines $(4,16)$. Furthermore, an increased expression of 1ncRNA H19 was reported to be associated with poor prognosis of patients with TC (4). However, the underlying molecular mechanisms remain to be fully elucidated. It has been reported that the overexpression of $\mathrm{H} 19$ in TC cell lines, including TPC-1 and NIM lines, promoted cell proliferation, migration and invasion, whereas the knockdown of H19 had the opposite effect and enhanced cell apoptosis (16). The exact molecular mechanisms remain to be investigated and confirmed.

In the present study, the expression of H19 in TC tissues was analyzed. Furthermore, the FTC-133 human TC cell line was used to assess the role of $\mathrm{H} 19$ in TC in vitro and to investigate the possible mechanisms.

\section{Materials and methods}

Tissue samples. The present study included 30 patients who underwent thyroidectomy for TC between May 2016 and June 2017 at the Fourth Hospital of Hebei Medical 
University (Shijiazhuang, China). The characteristics of the patients are listed in Table I. Samples of cancer tissues and adjacent normal tissues were collected, immediately frozen in liquid nitrogen and stored at $-80^{\circ} \mathrm{C}$ until use. The study protocol was approved by the Ethics Committee of the Fourth Hospital of Hebei Medical University and all patients provided written informed consent prior to participation in the study.

Cell culture. The human FTC-133 and TPC-1 TC cell lines were purchased from the Shanghai Institute of Cell Biology of the Chinese Academy of Sciences (Shanghai, China) and cultured in RPMI-1640 medium (Invitrogen; Thermo Fisher Scientific, Inc., Waltham, MA, USA) supplemented with $10 \%$ fetal bovine serum (Thermo Fisher Scientific, Inc.), $100 \mathrm{IU} / \mathrm{ml}$ penicillin and $100 \mathrm{mg} / \mathrm{ml}$ streptomycin (Invitrogen; Thermo Fisher Scientific, Inc.), and incubated at $37^{\circ} \mathrm{C}$ in a humidified atmosphere containing 5\% $\mathrm{CO}_{2}$. The cells were passaged every other day and cells in the logarithmic growth phase were used for the subsequent experiments.

Cell transfection. For the knockdown of lncRNA H19, two complementary oligonucleotides of small interfering (si)RNA, H19-siRNA1 and H19-siRNA2, and non-targeting control siRNA (NC) were designed. The sequences were chemically synthesized by Shanghai GeneChem Co., Ltd. (Shanghai, China). Using Lipofectamine $2000^{\mathrm{TM}}$ reagent (Invitrogen; Thermo Fisher Scientific, Inc.) following the manufacturer's protocol, the TC cells were transiently transfected with H19 siRNA (siRNA-1 or siRNA-2) or NC control. The mRNA levels were detected at $48 \mathrm{~h}$ post-transfection using a microspectrophotometer at a wavelength of $260 \mathrm{~nm}$. The most efficient siRNA was selected for the subsequent experiments.

Cell viability assay. The cells were seeded into a 96-well culture plate at a density of $5 \times 10^{4}$ cells/well. The cell viability was assessed using an MTT assay (Bio-Rad Laboratories, Inc., Hercules, CA, USA). Following the manufacturer's protocols, $10 \mu 1$ of MTT reagent $(5 \mathrm{mg} / \mathrm{ml})$ was added to each well, followed by incubation for $4 \mathrm{~h}$ at $37^{\circ} \mathrm{C}$. The supernatants were aspirated and the formazan crystals were dissolved in dimethylsulfoxide. The optical density of each well was measured using an ELISA reader (Bio-Rad Laboratories, Inc.) at a wavelength of $490 \mathrm{~nm}$ at 12,24 or $48 \mathrm{~h}$.

$R N A$ isolation and reverse transcription-quantitative polymerase chain reaction (RT-qPCR) analysis. Total RNA from the thyroid tissue and cells was extracted using TRIzol reagent (Invitrogen; Thermo Fisher Scientific, Inc.) according to the manufacturer's protocol. Total RNA was reverse-transcribed into complementary DNA with a PrimeScript ${ }^{\mathrm{TM}}$ RT reagent kit (Takara Biotechnology Co., Ltd., Dalian, China) and qPCR was performed using a SYBR ${ }^{\circledR}$ Premix Ex $\mathrm{Taq}^{\mathrm{TM}}$ kit (Takara Biotechnology Co., Ltd.) on an ABI 7300 Real-Time PCR system (Applied Biosystems; Thermo Fisher Scientific, Inc.) according to the manufacturers' protocols. The reactions were under the following conditions: $95^{\circ} \mathrm{C}$ for $7 \mathrm{~min} ; 40$ cycles of $95^{\circ} \mathrm{C}$ for $15 \mathrm{sec}, 60^{\circ} \mathrm{C}$ for $30 \mathrm{sec}$, and extension at $72^{\circ} \mathrm{C}$ for $30 \mathrm{sec}$. The relative expression of mRNA in each sample was normalized to GAPDH and calculated using the $2^{-\Delta \Delta \mathrm{Cq}}$ method (17). The primer sequences are listed in Table II.

Protein isolation and western blot analysis. The proteins were extracted from cells using ice-cold radioimmunoprecipitation assay lysis buffer (Beyotime Institute of Biotechnology, Haimen, China). The concentration of protein was determined using a BCA kit (Thermo Fisher Scientific, Inc.). Equal quantities of protein $(80 \mu \mathrm{g})$ were denatured in a boiling water bath and then separated by $10 \%$ SDS-PAGE, followed by transfer onto polyvinylidene difluoride membranes. Subsequently, the membranes were blocked with 5\% non-fat milk, and incubated with primary antibodies specific for B-cell lymphoma 2 (Bcl-2; cat. no. ab32124, 1:1,000, Abcam, Cambridge, MA, USA), Bcl-2-associated X protein (Bax; cat. no. ab32503, 1:1,000, Abcam), caspase 3 (cat. no. ab32351, 1:5,000, Abcam), phosphoinositide-3 kinase (p-PI3K; cat. no. ab109006, 1:1,000, Abcam), AKT (cat. no. ab133458, 1:1,000, Abcam) or GAPDH (cat. no. ab181603, $1: 10,000, \mathrm{Abcam})$ at $37^{\circ} \mathrm{C}$ for $1 \mathrm{~h}$. Following washing with PBS five times, the membranes were incubated with horseradish peroxidase-conjugated secondary antibodies (cat. no. ab205718, 1:2,000, Abcam) at room temperature for $60 \mathrm{~min}$, and bands were visualized with a Novex ${ }^{\circledR}$ ECL Chemiluminescent Substrate Reagent kit (Thermo Fisher Scientific, Inc.). Images were captured using a ChemiDoc ${ }^{\mathrm{TM}}$ $\mathrm{XRS}^{+}$imaging system (Bio-Rad Laboratories, Inc.). The signal intensities were quantified using ImageJ software 1.46 (National Institutes of Health, Bethesda, MD, USA).

Apoptosis assay. The apoptotic cells were quantified using an Annexin V-fluorescein isothiocyanate (FITC)/propidium iodide (PI) Apoptosis Detection kit (BD Biosciences, Franklin Lakes, NJ, USA) following the manufacturer's protocol. The cells were seeded in 6-well plates and stained with Annexin V/FITC for $15 \mathrm{~min}$ at room temperature in the dark, followed by the addition of PI for $5 \mathrm{~min}$ at room temperature in the dark. Finally, the cells were subjected to flow cytometric analysis (BD Biosciences) and analyzed using CellQuest software 5.1 (BD Biosciences).

Statistical analysis. All data were analyzed using SPSS 20.0 software (IBM Corp., Armonk, NY, USA). Values are expressed as the mean \pm standard deviation. Statistical significance was analyzed using Student's t-test. The difference among multiple groups were evaluated with one-way ANOVA followed by a Newman-Keuls post hoc test. $\mathrm{P}<0.05$ was considered to indicate a statistically significant difference.

\section{Results}

Characteristics of patients. As shown in Table I, the expression levels of H19 were significantly associated with histological grade $(\mathrm{P}=0.041)$, whereas there was no significant association between the expression of $\mathrm{H} 19$ and the gender $(\mathrm{P}=0.623)$ or ages of the patients (0.578).

lncRNA H19 is upregulated in TC tissues. RT-qPCR analysis was used to examine the expression of H19. The 
Table I. Expression of H19 in tissues from patients with thyroid cancer.

\begin{tabular}{lcc}
\hline Factor & Cases & H19 \\
\hline Gender & & \\
Male & 14 & $6.645 \pm 0.210$ \\
Female & 16 & $6.783 \pm 0.182$ \\
Age (years) & & \\
$<60$ & 17 & $6.661 \pm 0.239$ \\
$\geq 60$ & 13 & $6.848 \pm 0.215$ \\
Histological grade & & \\
Well-intermediately differentiated & 9 & $6.106 \pm 0.240$ \\
Poorly differentiated & 21 & $6.918 \pm 0.225$ \\
\hline
\end{tabular}

Values are presented as the mean \pm standard deviation.

Table II. Oligonucleotide primers used for quantitative polymerase chain reaction analysis.

\begin{tabular}{|c|c|}
\hline Name & Primer sequence \\
\hline \multirow[t]{2}{*}{ H19 } & Forward 5'-ACTCAGGAATCGGCTCTGGAA-3' \\
\hline & Reverse 5'-CTGCTGTTCCGATGGTGTCTT-3' \\
\hline \multirow[t]{2}{*}{ U6 } & Forward 5'-CTCGCTTCGGCAGCACA-3' \\
\hline & Reverse 5'-AACGCTTCACGAATTTGCGT-3' \\
\hline \multirow[t]{2}{*}{$\operatorname{Bax}$} & Forward 5'-CACCAGCTCTGAACAGATCATGA-3' \\
\hline & Reverse 5'-TCAGCCCATCTTCTTCCAGATGT-3' \\
\hline \multirow[t]{2}{*}{ Bcl-2 } & Forward 5'-CACCCCTGGCATCTTCTCCTT-3' \\
\hline & Reverse 5'-AGCGTCTTCAGAGACAGCCAG-3' \\
\hline \multirow[t]{2}{*}{ Caspase-3 } & Forward 5'-CATGGAAGCGAATCAATGGACT-3' \\
\hline & Reverse 5'-CTGTACCAGACCGAGATGTCA-3' \\
\hline \multirow[t]{2}{*}{ GAPDH } & Forward 5'-GGAGCGAGATCCCTCCAAAAT-3' \\
\hline & Reverse 5'-GGCTGTTGTCATACTTCTCATGG-3' \\
\hline
\end{tabular}

Bcl-2, B-cell lymphoma 2; Bax, Bcl-2-associated X protein.

results suggested that the levels of H19 in the TC tissues were significantly upregulated, by over six-fold, compared with those in the adjacent normal tissues (Fig. 1), which is consistent with the results of recent studies $(4,16)$. These results suggested that H19 may be involved in the development of TC.

H19 knockdown inhibits TC cell viability and induces apoptosis in vitro. The roles of $\mathrm{H} 19$ in TC were further investigated by assessing the cell viability and apoptosis of TC cells subjected to H19 knockdown. The knockdown efficiencies are shown in Fig. 2A and B. H19 siRNA-2 was selected for subsequent experiments due to its relatively higher efficiency. As indicated in Fig. 3A and B, H19 knockdown inhibited cell viability in a time-dependent manner, with a significant reduction at $48 \mathrm{~h}$ post-transfection. To further investigate the mechanisms by which $\mathrm{H} 19$ inhibits TC cell viability, the apoptotic rates of TC cells with H19 knockdown were assessed by flow cytometry. The results indicated that H19 silencing significantly enhanced the

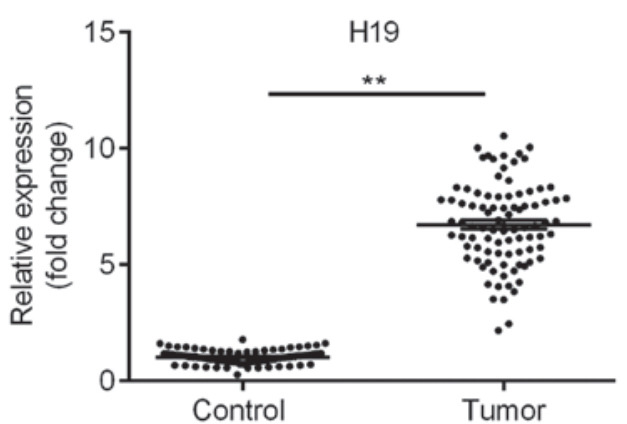

Figure 1. Long non-coding RNA H19 is upregulated in TC tissues. Reverse transcription-quantitative polymerase chain reaction analysis of the expression of $\mathrm{H} 19$ was performed in TC tissues. Results are expressed relative to the value of the normal control (set at 1 as the reference). The lines indicate the mean expression values. ${ }^{* *} \mathrm{P}<0.01$. TC, thyroid cancer.

apoptotic rate (Fig. 4A-D). Subsequently, whether H19 regulates the expression of the apoptosis-associated molecules Bax, Bcl-2 and caspase 3 was assessed $(18,19)$. As presented 

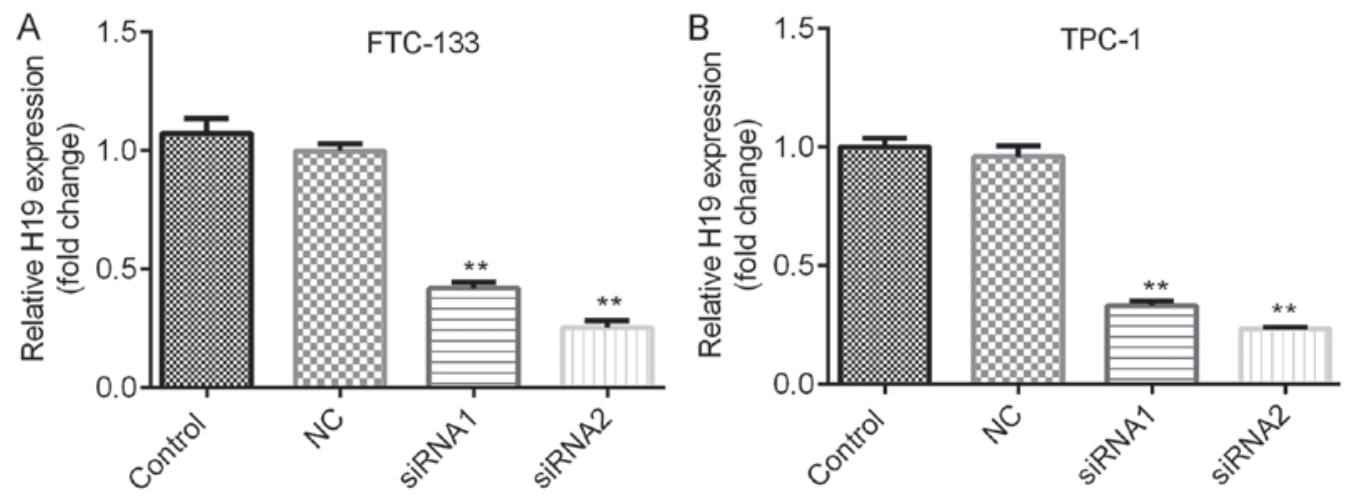

Figure 2. Expression of H19 in thyroid cancer cells. Reverse transcription-quantitative polymerase chain reaction analysis was performed to examine the expression of H19. (A) FTC-133 cells were transfected with NC siRNA, H19 siRNA1 or H19 siRNA2. Compared with that in the NC group, the expression of H19 was significantly decreased. (B) TPC-1 cells were transfected with NC siRNA, H19 siRNA1 or H19 siRNA2. Compared with that in the NC group, the expression of $\mathrm{H} 19$ was significantly decreased. Of note, $\mathrm{H} 19$ siRNA2 was more potent at suppressing the expression of $\mathrm{H} 19$. ${ }^{* *} \mathrm{P}<0.01$. Groups: NC, cells transfected with NC siRNA; siRNA1, cells transfected with H19 siRNA1; siRNA2, cells transfected with H19 siRNA2. NC, negative control; siRNA, small silencing RNA.
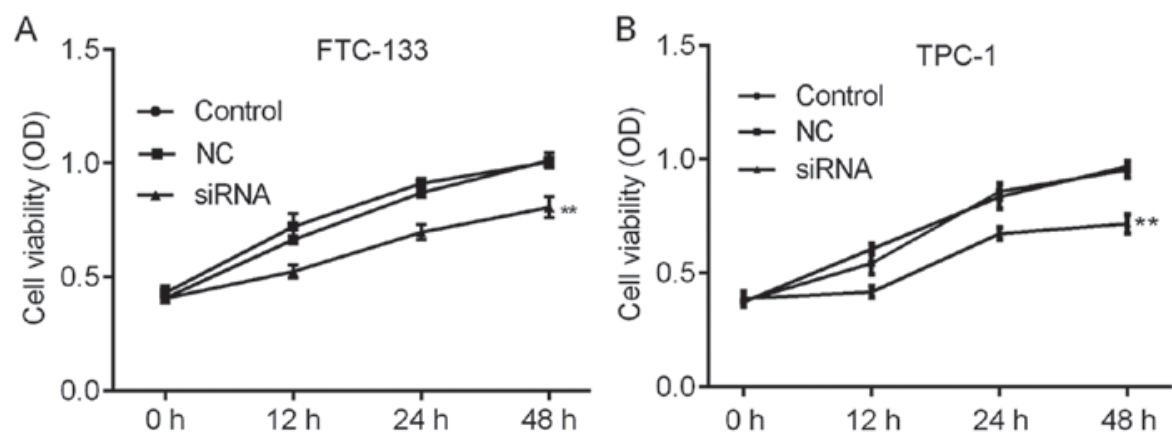

Figure 3. Knockdown of H19 reduces the viability of thyroid cancer cells. Cell viability was determined with an MTT assay. (A) Compared with that of the NC group cells, the viability of the FTC-133 cells was significantly decreased following treatment with H19 siRNA, while there was no significant difference between the control group and the NC group. (B) Compared with that of the NC group, the viability of TPC-1 cells was significantly decreased following treatment with H19 siRNA, while there was no significant difference between the control group and the NC group. ** P<0.01. Groups: NC, cells transfected with NC siRNA; siRNA, cells transfected with H19 siRNA. NC, negative control; siRNA, small silencing RNA.

in Figs. 5A-E and 6A-E, significant increases in Bax and caspase 3, and repression of Bcl-2 were observed at the mRNA and protein expression levels in TC cells following H19 silencing.

H19 may exert its functions in TC via the PI3K/AKT pathway. The PI3K/AKT signaling pathway has been reported to be associated with cell viability and apoptosis $(20,21)$. Therefore, whether PI3K/AKT signaling is involved in H19-mediated cellular responses was examined. As presented in Figs. 5D and E and 6D and E, H19 silencing induced a significant repression of p-PI3K and p-AKT, indicating that H19 exerts its cellular functions at least in partly through the PI3K/AKT signaling pathway.

\section{Discussion}

Increasing efforts have contributed to elucidating the molecular and cellular mechanisms underlying the progression of cancer, among which lncRNAs have attracted increasing attention (22). However, effective therapy for cancer remains limited (23), therefore, novel molecular signatures or potential molecular targets are urgently required. lncRNA H19 has been reported to have an oncogenic role in various types of cancer, including gastric cancer and cholangiocarcinoma $(24,25)$. However, current knowledge of H19 in TC is limited. In the present study, the expression of H19 was increased in TC tissues, indicating that H19 may be an oncogene in TC, which was consistent with previous studies $(24,25)$. The main types of TC are papillary thyroid cancer (PTC, $\sim 85 \%$ ) and follicular thyroid cancer (FTC, $10 \%$ ) (26). FTC is more aggressive and harder to diagnose than PTC and the 10-year survival rate is lower (27). Although the potential role of H19 has been reported in TC (28), the underlying mechanisms have remained unclear.

Previous studies have demonstrated that $\mathrm{H} 19$ suppresses the migration, invasion and cell viability of TC cells $(29,30)$. In the present study, it was found that downregulated H19 inhibited the cell viability and promoted apoptosis of FTC-133 and TPC-1 TC cells, which further verified H19 as an oncogene in TC. Liu et al reported that H19 regulated the proliferation, migration and invasion of TC cells via regulating the expression of miR-17-5p and YES1 (16). In addition, the overexpression of $\mathrm{H} 19$ has been shown to predict poor prognosis in patients with TC via regulating 
A
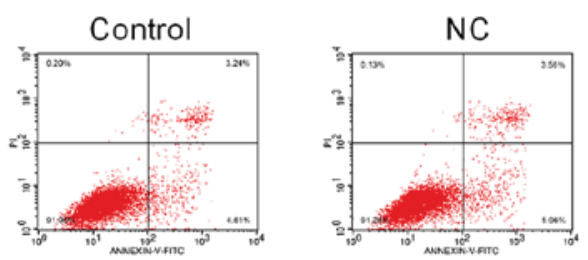

C

Control

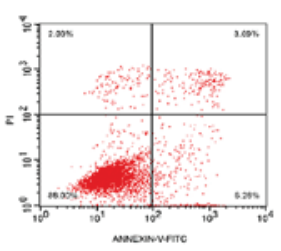

NC

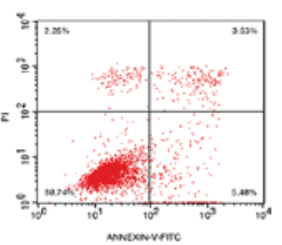

B 30
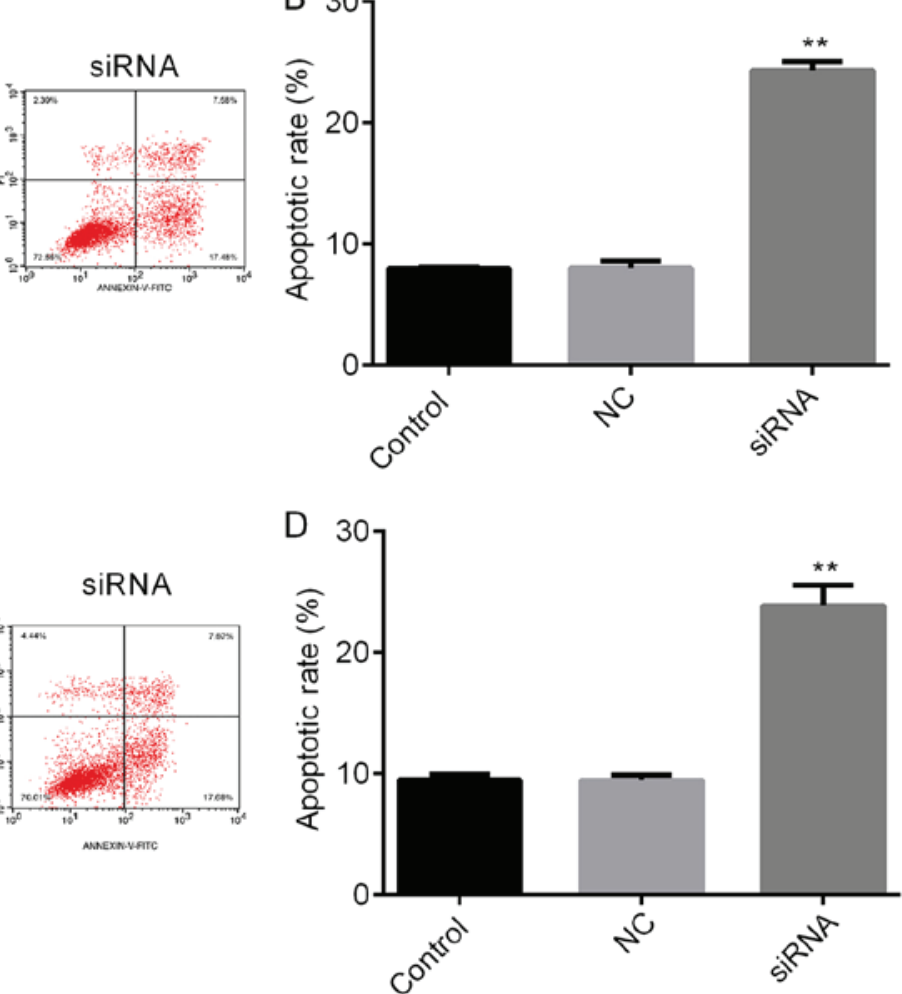

Figure 4. Knockdown of H19 promotes the apoptosis of thyroid cancer cells. Cell apoptosis was assessed using flow cytometry following Annexin V-FITC/PI staining. (A) Apoptosis of FTC-133 cells was markedly increased following transfection with H19 siRNA compared with that in the NC group. The differences between the control group and the NC group were not statistically significant. (B) Quantitative analysis of the apoptosis of FTC-133 cells. (C) Apoptosis of TPC-1 cells was markedly increased following transfection of H19 siRNA compared with that in the NC group. The differences between the control group and the NC group were not statistically significant. (D) Quantitative analysis of the apoptosis of TPC-1 cells. ${ }^{* *} \mathrm{P}<0.01$. Groups: NC, cells transfected with NC siRNA; siRNA, cells transfected with H19 siRNA. NC, negative control; siRNA, small silencing RNA; FITC, fluorescein isothiocyanate; PI, propidium iodide.
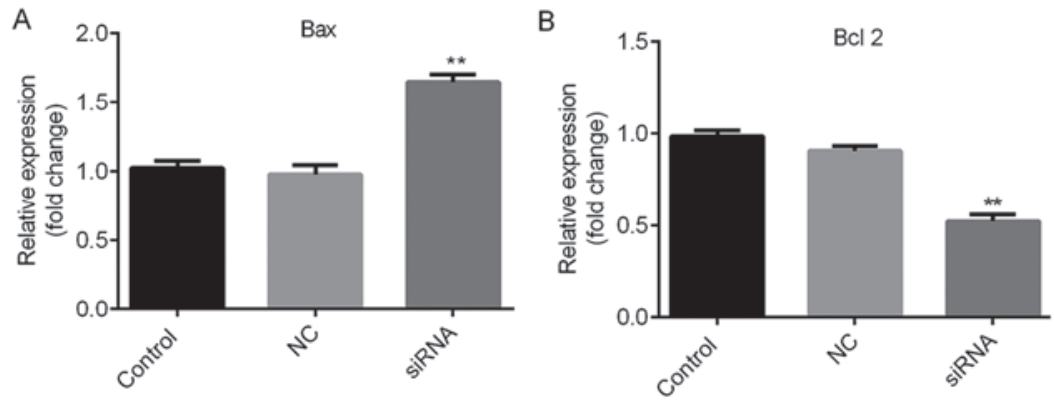

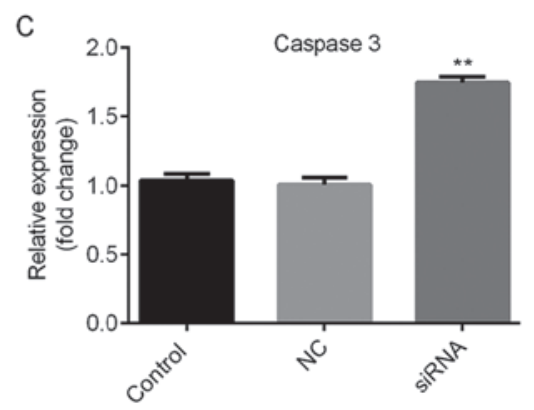

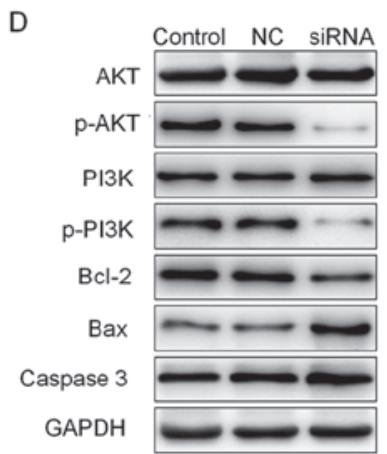

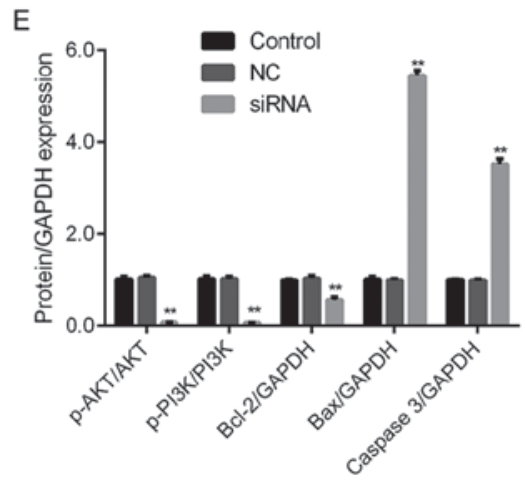

Figure 5. H19 may function through the Bax, Bcl2, caspase 3 and the PI3K/AKT pathway in FTC-133 cells. Thyroid cancer cells were transfected with H19 siRNA, NC or control, respectively. Reverse transcription-quantitative polymerase chain reaction analysis of (A) Bax, (B) Bcl-2 and (C) caspase 3 expression was performed. Results are expressed relative to the value of the $\mathrm{NC}$ group (set at 1 as the reference). (D) Representative western blot images for determining the expression of Bax, Bcl-2 and caspase 3, and the levels of p-PI3K and p-AKT protein. GAPDH was used as the loading control. (E) Quantitative analysis of relative changes in the proteins indicated above. ${ }^{* *} \mathrm{P}<0.01$. Groups: $\mathrm{NC}$, cells transfected with NC siRNA; siRNA, cells transfected with H19 siRNA. NC, negative control; siRNA, small silencing RNA; p-PI3K, phosphorylated phosphoinositide-3 kinase; Bax, Bcl-2-associated X protein; Bcl-2, B-cell lymphoma 2. 

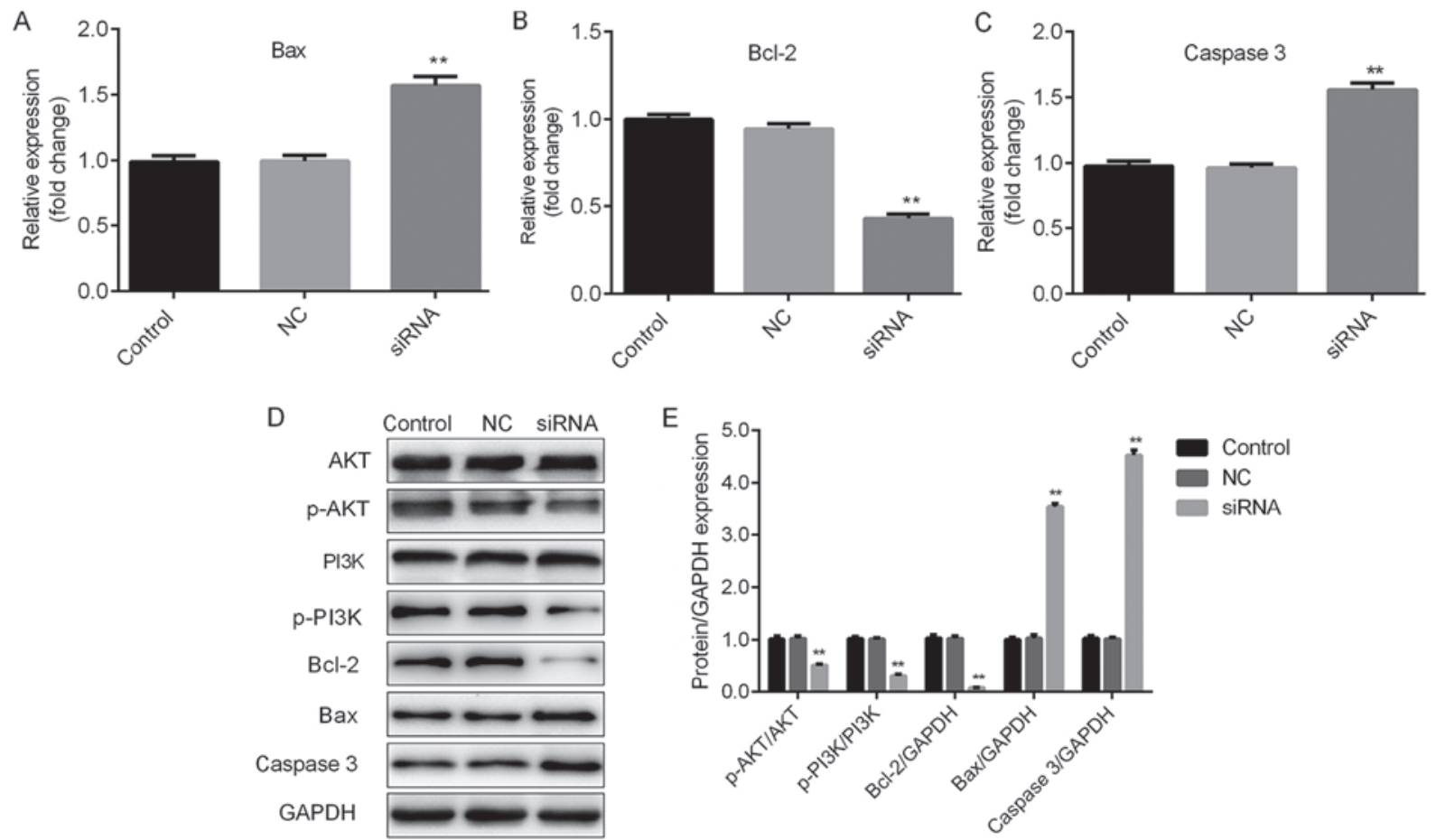

Figure 6. H19 may function through Bax, Bcl2, caspase 3 and the PI3K/AKT pathway in TPC-1 cells. Thyroid cancer cells were transfected with H19 siRNA, $\mathrm{NC}$ or control, respectively. Reverse transcription-quantitative polymerase chain reaction analysis of (A) Bax, (B) Bcl-2 and (C) caspase 3 expression was performed. Results are expressed relative to the value of the $\mathrm{NC}$ group (set at 1 as the reference). (D) Representative western blot images for determining the expression of Bax, Bcl-2 and caspase 3, and the levels of p-PI3K and p-AKT protein. GAPDH was used as the loading control. (E) Quantitative analysis of relative changes in the proteins indicated above. ${ }^{* *} \mathrm{P}<0.01$. Groups: NC, cells transfected with NC siRNA; siRNA, cells transfected with H19 siRNA. NC, negative control; siRNA, small silencing RNA; p-PI3K, phosphorylated phosphoinositide-3 kinase; Bax, Bcl-2-associated X protein; Bcl-2, B-cell lymphoma 2.

let-7 (31). The present study investigated whether H19 can regulate the viability and apoptosis of TC cells via other pathways.

The PI3K/AKT signaling pathway has an important role in tumorigenesis (32). Additionally, H19 has been shown to exert an oncogenic function by regulating the PI3K/AKT pathway in various types of cancer $(33,34)$. Bcl-2 and Bax are crucial in tumor cell apoptosis (35). Feng et al demonstrated that caspase 3 was associated the apoptosis of TC cells (36). In the present study, RT-qPCR and western blot analyses were performed to examine the mRNA and protein levels of Bcl-2/Bax, p-PI3K/AKT and caspase 3. The knockdown of H19 significantly suppressed Bcl-2, p-PI3K and p-AKT, and upregulated Bax and caspase 3, indicating that the suppression of H19 may have inhibited cell viability and promoted the apoptosis of TC cells via regulating Bcl-2/Bax, p-PI3K/AKT and caspase 3 .

However, the present study had limitations. First, the study was limited to by number of the patients enrolled. Second, all the experiments performed in the study was in vitro, thus in vivo experiments are required in further investigations.

In conclusion, H19 was upregulated in TC tissues. The effects of decreased H19 were broadly similar in suppressing the proliferation and promoting the apoptosis of the FTC-133 FTC cell line and TPC-1 PTC cell line, suggesting that H19 may be applicable as a target across different types of TC.

\section{Acknowledgements}

Not applicable.

\section{Funding}

No funding was received.

\section{Availability of data and materials}

The datasets used and/or analyzed during the current study are available from the corresponding author on reasonable request.

\section{Authors' contributions}

XL prepared the manuscript and performed experiments with the assistance of QL. XJ collected the data and provided interpretation with the assistance of HG. YL conceived and designed the current study.

\section{Ethics approval and consent to participate}

The study protocol was approved by the Ethics Committee of the Fourth Hospital of Hebei Medical University and all patients provided written informed consent prior to participation in the study.

\section{Patient consent for publication}

Not applicable.

\section{Competing interests}

The authors declare that they have no competing interests. 


\section{References}

1. Klubo-Gwiezdzinska J, Yang L, Merkel R, Patel D, Nilubol N, Merino MJ, Skarulis M, Sadowski SM and Kebebew E: Results of screening in familial non-medullary thyroid cancer. Thyroid 27 : 1017-1024, 2017

2. Aschebrook-Kilfoy B, James B, Nagar S, Kaplan S, Seng V, Ahsan H, Angelos P, Kaplan EL, Guerrero MA, Kuo JH, et al: Risk factors for decreased quality of life in thyroid cancer survivors: Initial findings from the North American thyroid cancer survivorship study. Thyroid 25: 1313-1321, 2015.

3. Grogan RH, Kaplan SP, Cao H, Weiss RE, Degroot LJ, Simon CA, Embia OM, Angelos P, Kaplan EL and Schechter RB: A study of recurrence and death from papillary thyroid cancer with 27 years of median follow-up. Surgery 154: 1436-1447, 2013.

4. Gillanders SL and O'Neill JP: Prognostic markers in well differentiated papillary and follicular thyroid cancer (WDTC). Eur J Surg Oncol 44: 286-296, 2018.

5. Jeong S, Lee J, Kim D, Seol MY, Lee WK, Jeong JJ, Nam KH, Jung SG, Shin DY, Lee EJ, et al: Relationship of focally amplified long noncoding on chromosome 1 (FAL1) lncRNA with E2F transcription factors in thyroid cancer. Medicine (Baltimore) 95: e2592, 2016.

6. Mercer TR, Dinger ME and Mattick JS: Long non-coding RNAs: Insights into functions. Nat Rev Genet 10: 155-159, 2009.

7. Hao S, Yao L, Huang J, He H, Yang F, Di Y, Jin C and Fu D: Genome-wide analysis identified a number of dysregulated long noncoding RNA (lncRNA) in human pancreatic ductal adenocarcinoma. Technol Cancer Res Treat 17: 1533034617748429, 2018.

8. Ponzio G, Rezzonico R, Bourget I, Allan R, Nottet N, Popa A, Magnone V, Rios G, Mari B and Barbry P: A new long noncoding RNA (lncRNA) is induced in cutaneous squamous cell carcinoma and down-regulates several anticancer and cell differentiation genes in mouse. J Biol Chem 292: 12483-12495, 2017.

9. Zhao JH, Sun JX, Song YX, Chen XW, Yang YC, Ma B, Wang J, Gao $\mathrm{P}$ and Wang ZN: A novel long noncoding RNA-LOWEG is low expressed in gastric cancer and acts as a tumor suppressor by inhibiting cell invasion. J Cancer Res Clin Oncol 142: 601-609, 2016.

10. Chen C, Zhou L, Wang H, Chen J, Li W, Liu W, Shen M, Liu H and $\mathrm{Fu} \mathrm{X}$ : Long noncoding RNA CNALPTC1 promotes cell proliferation and migration of papillary thyroid cancer via sponging miR-30 family. Am J Cancer Res 8: 192-206, 2018.

11. Li T, Yang XD, Ye CX, Shen ZL, Yang Y, Wang B, Guo P, Gao ZD, Ye YJ, Jiang KW and Wang S: Long noncoding RNA HIT000218960 promotes papillary thyroid cancer oncogenesis and tumor progression by upregulating the expression of high mobility group AT-hook 2 (HMGA2) gene. Cell Cycle 16: 224-231, 2017

12. Jendrzejewski J, He H, Radomska HS, Li W, Tomsic J, Liyanarachchi S, Davuluri RV, Nagy R and de la Chapelle A: The polymorphism rs 944289 predisposes to papillary thyroid carcinoma through a large intergenic noncoding RNA gene of tumor suppressor type. Proc Natl Acad Sci USA 109: 8646-8651, 2012.

13. Jendrzejewski J, Thomas A, Liyanarachchi S, Eiterman A, Tomsic J, He H, Radomska HS, Li W, Nagy R, Sworczak K and de la Chapelle A: PTCSC3 is involved in papillary thyroid carcinoma development by modulating S100A4 gene expression. J Clin Endocrinol Metab 100: E1370-E1377, 2015.

14. Zheng H, Wang M, Jiang L, Chu H, Hu J, Ning J, Li B, Wang D and Xu J: BRAF-activated long noncoding RNA modulates papillary thyroid carcinoma cell proliferation through regulating thyroid stimulating hormone receptor. Cancer Res Treat 48: 698-707, 2016

15. Wang Y, Guo Q, Zhao Y, Chen J, Wang S, Hu J and Sun Y: BRAF-activated long non-coding RNA contributes to cell proliferation and activates autophagy in papillary thyroid carcinoma. Oncol Lett 8: 1947-1952, 2014.

16. Liu L, Yang J, Zhu X, Li D, Lv Z and Zhang X: Long noncoding RNA H19 competitively binds miR-17-5p to regulate YES1 expression in thyroid cancer. FEBS J 283: 2326-2339, 2016.

17. Livak KJ and Schmittgen TD: Analysis of relative gene expression data using real-time quantitative PCR and the 2(-Delta Delta C(T)) method. Methods 25: 402-408, 2001.
18. Mei JM and Niu CS: Effects of CDNF on 6-OHDA-induced apoptosis in $\mathrm{PC} 12$ cells via modulation of $\mathrm{Bcl}-2 / \mathrm{Bax}$ and caspase-3 activation. Neurol Sci 35: 1275-1280, 2014.

19. Pal MK, Jaiswar SP, Srivastav AK, Goyal S, Dwivedi A, Verma A, Singh J, Pathak AK, Sankhwar PL and Ray RS: Synergistic effect of piperine and paclitaxel on cell fate via cyt-c, Bax/Bcl-2-caspase-3 pathway in ovarian adenocarcinomas SKOV-3 cells. Eur J Pharmacol 791: 751-762, 2016.

20. Liao YX, Zhang ZP, Zhao J and Liu JP: Effects of fibronectin 1 on cell proliferation, senescence and apoptosis of human glioma cells through the PI3K/AKT signaling pathway. Cell Physiol Biochem 48: 1382-1396, 2018.

21. Zhou Y, Li S, Li J, Wang D and Li Q: Effect of microRNA-135a on cell proliferation, migration, invasion, apoptosis and tumor angiogenesis through the IGF-1/PI3K/Akt signaling pathway in non-small cell lung cancer. Cell Physiol Biochem 42: 1431-1446, 2017.

22. de Oliveira JC, Oliveira LC, Mathias C, Pedroso GA, Lemos DS, Salviano-Silva A, Jucoski TS, Lobo-Alves SC, Zambalde EP, Cipolla GA and Gradia DF: Long non-coding RNAs in cancer: Another layer of complexity. J Gene Med 21: e3065, 2019.

23. Tang Y, Soroush F, Tong Z, Kiani MF and Wang B: Targeted multidrug delivery system to overcome chemoresistance in breast cancer. Int J Nanomedicine 12: 671-681, 2017.

24. Yan J, Zhang Y, She Q, Li X, Peng L, Wang X, Liu S, Shen X, Zhang W, Dong Y, et al: Long noncoding RNA H19/miR-675 axis promotes gastric cancer via FADD/Caspase 8/Caspase 3 signaling pathway. Cell Physiol Biochem 42: 2364-2376, 2017.

25. Xu Y, Wang Z, Jiang X and Cui Y: Overexpression of long noncoding RNA H19 indicates a poor prognosis for cholangiocarcinoma and promotes cell migration and invasion by affecting epithelial-mesenchymal transition. Biomed Pharmacother 92: 17-23, 2017.

26. Rothhut B, Ghoneim C, Antonicelli F and Soula-Rothhut M: Epidermal growth factor stimulates matrix metalloproteinase-9 expression and invasion in human follicular thyroid carcinoma cells through focal adhesion kinase. Biochimie 89: 613-624, 2007.

27. Dettmer M, Perren A, Moch H, Komminoth P, Nikiforov YE and Nikiforova MN: Comprehensive MicroRNA expression profiling identifies novel markers in follicular variant of papillary thyroid carcinoma. Thyroidology 23: 1383-1389, 2013.

28. Murugan AK, Munirajan AK and Alzahrani AS: Long noncoding RNAs: Emerging players in thyroid cancer pathogenesis. Endocr Relat Cancer 25: R59-R82, 2018.

29. Wang P, Liu G, Xu W, Liu H, Bu Q and Sun D: Long noncoding RNA H19 inhibits cell viability, migration, and invasion via downregulation of IRS-1 in thyroid cancer cells. Technol Cancer Res Treat 16: 1102-1112, 2017.

30. Mahmoudian-Sani MR, Jalali A, Jamshidi M, Moridi H, Alghasi A, Shojaeian A and Mobini GR: Long non-coding RNAs in thyroid cancer: Implications for pathogenesis, diagnosis, and therapy. Oncol Res Treat 42: 136-142, 2019.

31. Liu N, Zhou Q, Qi YH, Wang H, Yang L and Fan QY: Effects of long non-coding RNA H19 and microRNA let7a expression on thyroid cancer prognosis. Exp Mol Pathol 103: 71-77, 2017.

32. Lee KT, Gopalan V and Lam AK: Roles of long-non-coding RNAs in cancer therapy through the PI3K/Akt signalling pathway. Histol Histopathol 34: 593-609, 2019.

33. Wang SH, Wu XC, Zhang MD, Weng MZ, Zhou D and Quan ZW: Long noncoding RNA H19 contributes to gallbladder cancer cell proliferation by modulated miR-194-5p targeting AKT2. Tumour Biol 37: 9721-9730, 2016.

34. Liao Z, Zhao J and Yang Y: Downregulation of lncRNA H19 inhibits the migration and invasion of melanoma cells by inactivating the NF- $\mathrm{B}$ and PI3K/Akt signaling pathways. Mol Med Rep 17: 7313-7318, 2018.

35. Renault TT, Dejean LM and Manon S: A brewing understanding of the regulation of Bax function by Bcl-xL and $\mathrm{Bcl}-2$. Mech Ageing Dev 161: 201-210, 2017.

36. Feng K, Liu Y, Xu LJ, Zhao LF, Jia CW and Xu MY: Long noncoding RNA PVT1 enhances the viability and invasion of papillary thyroid carcinoma cells by functioning as ceRNA of microRNA-30a through mediating expression of insulin like growth factor 1 receptor. Biomed Pharmacother 104: 686-698, 2018. 